\title{
Comportamentos de estudo realizados por estudantes para preparar-se para provas de desempenho acadêmico
}

\author{
João Fernando Rech Wachelke \\ Sílvio Paulo Botomé \\ Universidade Federal de Santa Catarina
}

\begin{abstract}
RESUMO
Elaborar sobre o que é estudado, como ao escrever sobre um texto com as próprias palavras, é preferível à mera repetição. Estudantes que utilizam com freqüência comportamentos de elaboração de assuntos provavelmente são eficientes e alcançam bons resultados acadêmicos. Assim, cabe investigar se existem diferenças na frequiência de utilização de procedimentos de estudo durante a preparação para uma prova acadêmica por parte de sujeitos bem sucedidos e mal sucedidos nela. Participaram do estudo 145 sujeitos, 53 deles recém-aprovados num vestibular concorrido e 56 reprovados; também participaram 23 aprovados num vestibular de exigência mediana e 13 reprovados. Eles responderam um questionário sobre a freqüência de utilização de procedimentos de estudo durante a preparação para o vestibular, agrupados por graus de complexidade, desde procedimentos superficiais, como sublinhar, a complexos, como resolver exercícios. Analisando os resultados, observa-se que procedimentos de resolução de exercícios provavelmente contribuem mais para a aprovação em provas de vestibular ou semelhantes, pois mais aprovados utilizaram essas práticas com alta freqüência que reprovados, o que não foi encontrado claramente em relação aos outros procedimentos. São discutidas explicações plausíveis para a eficácia de resolver exercícios, decorrências das descobertas para instituições de ensino e sugestões para estudos subseqüentes.
\end{abstract}

Palavras-chave: procedimentos de estudo; comportamento de estudar; exigência de desempenho.

\begin{abstract}
Study behaviors used by students during preparation for academic performance tests

Thinking about what is being studied, through writing about a text with one's own words for example, is preferable to mere repetition. Students who use frequently such behavior of content elaboration often are probably effective and achieve good academic performance. Thus, it is relevant to investigate whether there are differences in the frequency of use of study procedures during the preparation for an academic test on the part of students who are successful and unsuccessful in it. One hundred and forty-five subjects took part on the study, 53 of whom had been approved in the entrance examinations for a challenger university course, and 56 who had been failed in it; 23 individuals approved in exams with average difficulty and 13 who had failed it also participated. They answered a questionnaire on the frequency of use of study procedures during the preparation for the exam, grouped by level of complexity, from superficial procedures like underlining, to complex ones such as solving exercises. The analysis of the results shows that procedures involving the resolution of exercises probably offer a higher contribution for the approval in university admission exams and similar tests, since a higher frequency of successful individuals used those practices more than the individuals who failed. The same was not clearly observed concerning other procedures. Possible explanations for the efficacy of exercise-solving, consequences of these findings for educational institutions and suggestions for further studies are also discussed.
\end{abstract}

Keywords: study procedures; study behavior; performance demand.

As características do comportamento de estudar são dados importantes da vida acadêmica de todos os indivíduos inseridos no sistema educacional formal. No contexto escolar, é possível afirmar que estudar envolve os comportamentos realizados pelos indivíduos com a finalidade de fortalecer aprendizagens relativas a exigências educacionais. Quando se fala de estudo voltado para escolas ou provas acadêmicas, geralmente essas exigências traduzem-se em repertórios comportamentais que necessitam estar presentes para os alunos, tais como conhecer e relacionar informações históricas ou científicas, entender e empregar regras aritméticas e lógicas para resolver problemas, falar línguas estrangeiras e assim por diante. Essa definição de estudar é ampla e inclui tanto os comportamentos que têm lugar em sala de aula, como prestar atenção à exposição de um professor, quanto outros que ocorrem fora dela, como ler textos ou realizar exercícios. 
Um aspecto importante do estudar, principalmente quando o estudo é individual e ocorre fora de sala de aula, envolve os comportamentos de pensar sobre os próprios pensamentos envolvidos nas situações de estudo, tais como planejar, predizer e monitorar o processo de aprender (Dembo, 1988). São relações entre situações antecedentes, respostas do estudante e situações conseqüentes voltadas para a interferência em seus próprios processos de aprendizagem. No que diz respeito ao estudo individual, ou pelo menos exterior à sala de aula, é feita referência a comportamentos de autocontrole, que produzem as condições que aumentam a probabilidade de ocorrência de outros comportamentos de interesse (Skinner, 1953, com tradução em português, de 1967).

Dentre as várias formas que pode assumir o comportamento de estudar, uma delas é o estudo externo à sala de aula para dominar assuntos, com a finalidade de obter um bom desempenho em uma prova acadêmica. Uma compreensão mais abrangente dos comportamentos de estudo dessa natureza é algo importante devido à freqüência com que as pessoas deparam-se com esse tipo de situação: em seleções para cargos profissionais, exames de acesso a instituições educacionais e assim por diante (Wachelke \& Botomé, 2004).

A obtenção de um bom aproveitamento num teste de desempenho provavelmente é decorrência de uma multiplicidade de fatores como, por exemplo, a condição emocional do indivíduo que presta a prova no momento de sua realização. Entre esses fatores, cabe incluir a preparação para o exame em questão, por meio da qual o examinando capacita-se a responder com correção às demandas da prova com maior probabilidade de sucesso em relação aos indivíduos que simplesmente dependem da combinação de variáveis sobre as quais eles exercem nenhuma ou pouca interferência por meio de seu próprio comportamento. Nesse sentido, é feita referência ao comportamento de estudar e a aspectos específicos de sua ocorrência.

No que se refere a aspectos quantitativos do comportamento de estudar em geral, é mencionada a alocação de tempo para estudo de diferentes materiais. Esse fenômeno foi e continua sendo pesquisado extensamente segundo a perspectiva cognitivista de processamento de informação (ver Boruchovitch, 1999; Mazzoni \& Cornoldi, 1993; Metcalfe, 2002; Nelson \& Leonesio, 1988; Nelson, 1993; Son \& Metcalfe, 2000).

Já em relação à distribuição do estudo no tempo ao realizar a preparação para uma prova de exigência de desempenho, foi feito um estudo para verificar a existência de diferenças na maneira como estudantes aprovados e reprovados em provas de dificuldades alta e mediana administram o tempo de estudo durante o período de preparação para uma prova. Foi observa- do que os grupos de participantes que prestaram uma prova da mesma dificuldade, tanto aprovados quanto reprovados, são equivalentes no modo como alocam tempo para seu estudo. Por outro lado, mais participantes que se prepararam para a prova de alta exigência estudaram com grande intensidade, em relação aos participantes que enfrentaram a condição de exigência intermediária (Wachelke \& Botomé, 2004).

A fim de alcançar um entendimento pelo menos preliminar desse fenômeno e seus determinantes, torna-se imperativo pesquisar outros tipos de comportamentos realizados durante as ocasiões de estudo, uma vez que as diferenças de alocação de tempo e intensidade de estudo não explicam desempenhos diferenciados numa dada condição de exigência representada por uma prova acadêmica. Um exemplo de aspecto dessa natureza relaciona-se à natureza física do ambiente de estudo, que se mostra mais adequado para estudar se não existirem estimulações auditivas e visuais concorrentes com a estimulação relacionada ao estudo (Jabur, 1985).

Outra possibilidade de investigação do comportamento de estudar reside nos procedimentos concretos realizados por estudantes nas sessões de estudo. Nesse contexto, a questão deixa de ser quanto tempo os participantes estudam para se preparar para uma prova, mas sim, o que fazem durante o tempo em que estudam. Se por um lado um estudante pode dedicar seu tempo de estudo a elaborar resumos, um outro pode dar preferência à confecção de esquemas de relações para melhor apreender o que está sendo estudado. Um terceiro pode dedicar-se a realizar exercícios e outros ainda podem usar procedimentos diferentes desses.

Alguns desses procedimentos são mais eficazes que outros para garantir àquele que os utiliza um aprendizado útil, sobretudo quando é necessário enfrentar uma situação de exigência de desempenho. Segundo Botomé (1979), comportamentos caracterizados pela elaboração sobre o que está sendo estudado como, por exemplo, escrever sobre um texto com as próprias palavras, são preferíveis em relação a comportamentos de identificação, reconhecimento ou repetição como sublinhar palavras e frases ou copiar trechos textuais.

É pertinente, portanto, examinar a seguinte pergunta de pesquisa: há diferenças na freqüência de utilização de procedimentos de estudo durante o período de preparação para uma prova acadêmica, por parte de participantes bem sucedidos e mal sucedidos nessa prova? Em caso de resposta afirmativa, quais seriam essas diferenças? Qual seu potencial para explicar o desempenho diferenciado desses dois grupos de participantes? E o que acontece no caso de condições de exigência diferenciadas?

Para responder em parte a essas questões é relevante estudar a preparação de estudantes para uma 
prova, ocasião em que a necessidade de organizar os processos de estudo exacerba-se. Além disso, os estudantes necessitam efetivamente estudar para obter desempenho satisfatório em provas com impacto em suas vidas, tais como, por exemplo, o vestibular. Os exames vestibulares, nesse sentido, podem ser considerados como uma situação ou contexto privilegiado para pesquisar o comportamento de estudar frente a exigências de desempenho, no que diz respeito aos procedimentos empregados pelos estudantes (Wachelke \& Botomé, 2004).

\section{MÉTODO}

\section{Participantes}

Participaram como participantes 145 indivíduos, os quais haviam prestado vestibular no ano anterior à coleta de dados. Cento e nove desses participantes haviam realizado um vestibular para um curso de medicina de uma universidade federal, prova que exigiu pelo menos 78,27\% de índice de acertos dos candidatos para que eles fossem aprovados, e, portanto, foi considerada uma condição de alta exigência. Outros trinta e seis participantes prestaram vestibular para um curso de Design da mesma instituição, que exigiu $60,67 \%$ de acertos dos aprovados, e consistiu na condição de exigência mediana.

Por sua vez os participantes que prestaram provas foram separados conforme terem sido aprovados ou reprovados no exame. Desse modo, resultou uma subdivisão em quatro grupos: aprovados na condição de alta exigência, reprovados na condição de alta exigência, aprovados na condição de exigência mediana e reprovados nessa condição.

O grupo de participantes aprovados em alta exigência foi composto por 53 participantes $(41,5 \%$ de mulheres), com idade média de 19 anos e 11 meses (desvio padrão: 2,2 anos). Os reprovados nessa condição foram 56 participantes $(55,4 \%$ de mulheres $)$, cuja idade média foi 18 anos e 7 meses (desvio padrão: 1,1 anos). Os aprovados na condição de alta exigência foram 23 (47,8\% de mulheres) e possuíam idade média de 19 anos e 2 meses (desvio padrão: 1,8 anos). Por sua vez, os 13 reprovados na condição de exigência mediana (61,5\% de mulheres) tinham idade média de 18 anos e 1 mês (desvio padrão: 1,5 anos).

\section{Situação e ambiente}

Os participantes responderam individualmente a um questionário de pesquisa e o fizeram nas salas de aula da universidade ou dos cursos pré-vestibulares, dependendo da instituição a que os participantes estavam vinculados, em horários especialmente reservados para a coleta de dados. Enquanto eles respondiam ao questionário, o professor, com quem teriam aula posteriormente e um dos pesquisadores, responsável pela pesquisa em realização, estavam presentes na sala de aula.

\section{Material}

Um questionário foi utilizado como forma de obtenção de dados para a pesquisa. O questionário era formado por duas partes: a primeira era composta por perguntas de múltipla escolha acerca da caracterização dos participantes, com questões sobre idade, gênero e o curso para o qual havia prestado vestibular no ano da coleta de dados.

A segunda parte constituía o núcleo de investigação da pesquisa, contendo perguntas de múltipla escolha sobre o grau de frequiência com que os participantes haviam utilizado seis tipos de procedimentos durante o ano de estudo. Os participantes deveriam indicar, numa escala de 1 (nunca) a 8 (em todas as sessões de estudo) se eles utilizaram os seguintes procedimentos: (1) uso de estratégias de memorização ("macetes", rimas etc. que têm por objetivo trazer à memória mais facilmente detalhes de conteúdo difíceis ou essenciais); (2) uso de estratégias de destaque de informação (sublinhar, grifar, circular etc. informações julgadas importantes contidas em textos de estudo); (3) elaboração, com as próprias palavras, de resumos contendo aspectos essenciais dos conteúdos; (4) uso de processos de esquematização dos assuntos estudados (divisão em tópicos, construção de diagramas e desenhos etc.); (5) resolução de exercícios de vestibulares passados da universidade para que estavam prestando concurso; e (6) resolução de exercícios de vestibulares passados de outras universidades.

Esses procedimentos podem ser agrupados em três blocos, conforme o grau de complexidade das respostas que eles fortalecem. O primeiro bloco, que compreende os procedimentos memorizar e destacar informações, diz respeito a estratégias voltadas para um domínio mais simples e superficial dos conteúdos estudados. Privilegia-se um modelo repetitivo de aprendizagem, em que o aluno não necessariamente entende as informações que busca "decorar". Um bloco de procedimentos intermediários, resumir e esquematizar, exige maior engajamento do indivíduo. Fazer resumos e esquemas implica sintetizar ou identificar componentes principais do material a ser estudado, o que favorece a percepção por parte de estudantes sobre as relações dos assuntos entre si. Por fim, o terceiro bloco consiste em resolver exercícios, seja de vestibulares anteriores ou de outros vestibulares, envolvendo assim uma participação ativa do indivíduo para solucionar problemas com seu conhecimento.

\section{Procedimento}


Foram observados estudantes que tivessem prestado o vestibular no ano anterior à coleta de dados, de modo a aumentar a probabilidade de lembranças fidedignas de sua rotina de estudos. Em decorrência do período em que ocorreu a coleta de dados, participaram alunos que estavam entrando na universidade nos cursos de Medicina e Design, tendo sido aprovados em primeira chamada para ingressar na universidade no segundo semestre.

Em relação aos participantes reprovados, foram consideradas as instituições em que havia maior probabilidade de serem encontrados estudantes reprovados no vestibular recentemente: os cursos prévestibulares, popularmente conhecidos como cursinhos. Para encontrar os participantes desejados nos cursinhos, foram utilizadas listas que continham as opções de cursos dos vestibulandos em simulados no ano da coleta de dados.

O contato com a universidade e cursos prévestibulares efetuou-se através dos coordenadores dos cursos de graduação e secretários dos cursos, respectivamente. Foi apresentada uma carta de solicitação às pessoas que exerciam essas funções e solicitada autorização para coletar os dados com os alunos. Posteriormente, foram agendados horários para a aplicação dos questionários.

Na ocasião da coleta de dados, os pesquisadores apresentaram-se e explicaram em linhas gerais sobre o que era a pesquisa. Foi comunicado aos alunos que a resposta ao questionário era voluntária e anônima. Embora já constasse das instruções do instrumento, foi destacado que as respostas deveriam dizer respeito apenas ao estudo para o último vestibular realizado.

口Aprovados Alta 口Reprovados Alta

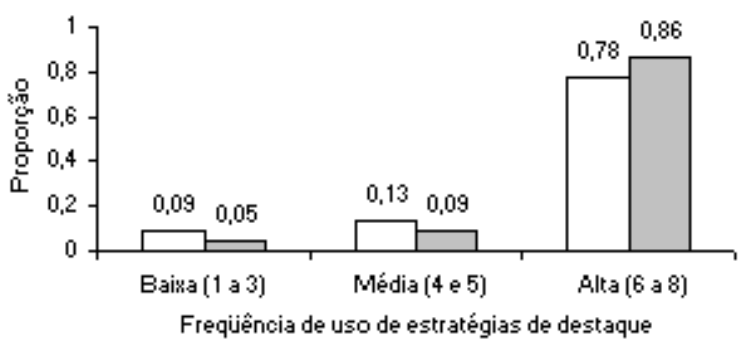

Foi fornecido também endereço de correio eletrônico de um dos pesquisadores para contato. Não houve limite de tempo para resposta aos questionários. Em média, os participantes demoraram aproximadamente vinte e cinco minutos para responder o instrumento. Os pesquisadores estiveram à disposição para atendêlos, caso tivessem dúvidas sobre como preenchê-lo.

\section{RESULTADOS}

Na Figura 1 são comparados os participantes aprovados e reprovados nas duas condições de exigência quanto à frequiência de utilização de estratégias de destaque (sublinhar, grifar, circular etc.) de informação na preparação para o vestibular. Proporcionalmente mais reprovados em alta exigência declaram usar essa estratégia em grande parte das sessões de estudo $(0,86)$ em comparação com aprovados $(0,78)$. Entre os participantes que prestaram vestibular na condição de média exigência, as proporções de participantes aprovados e reprovados que empregam essa estratégia com baixa frequiência são semelhantes, próximas de um quinto $(0,20)$. Nenhum participante reprovado afirmou utilizar-se desse tipo de procedimento com freqüência mediana, contrastando com cerca de um quarto dos aprovados $(0,26)$ que se situam nessa faixa. Em compensação, uma proporção de 0,77 dos reprovados afirma destacar informação com alta frequiência no estudo para o vestibular, enquanto pouco mais da metade dos aprovados emprega essa estratégia.

口Aprovados Média aReprovados Média

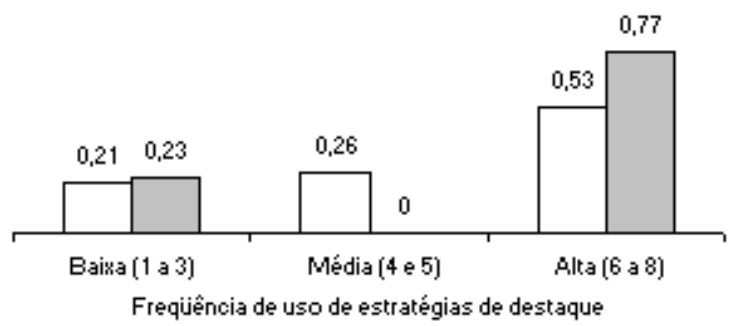

Figura 1: Distribuição das proporções de sujeitos que prestaram provas para o vestibular nas condições de exigência alta e média no que diz respeito à frequiência de uso de estratégias de destaque durante o ano de preparação para o vestibular.

Conforme representação na Figura 2, os participantes reprovados na condição de alta exigência utilizam estratégias de memorização com freqüência ligeiramente maior que os aprovados. Ainda que a proporção de participantes que afirma fazer uso da memorização com alta freqüência seja quase igual nos dois grupos, proporcionalmente mais participantes reprovados afirmam memorizar com freqüência mediana nas sessões de estudo para o vestibular, e conseqüentemente menos reprovados dizem utilizar-se de estra- tégias de memorização em poucas sessões de estudo. Já entre os estudantes que prestaram vestibular na condição de média exigência, embora uma proporção ligeiramente maior de aprovados afirme utilizar a memorização de forma intensa nas sessões de estudo ( 0,52 contra 0,46 dos reprovados), eles também possuem superioridade proporcional de maior magnitude em relação aos reprovados que dizem memorizar com baixa frequiência. A proporção de reprovados que memoriza com frequiência mediana no estudo para o 
vestibular é consideravelmente maior que a de apro-

口Aprovados Alta qReprovados Alta

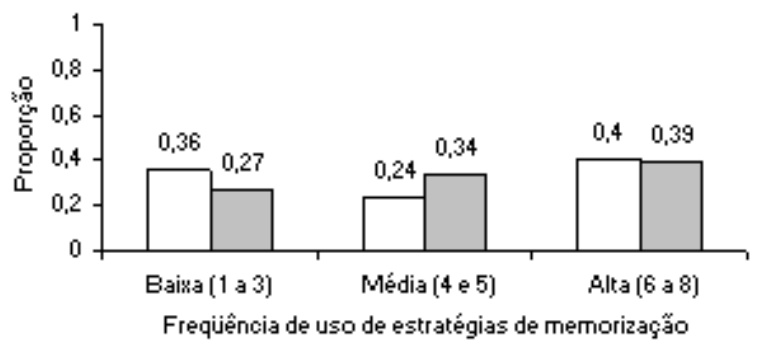

vados: 0,39 e 0,09 , respectivamente.

Figura 2: Distribuição das proporções de sujeitos que prestaram provas para o vestibular nas condições de exigência alta e média no que diz respeito à frequiência de uso de estratégias de memorização durante o ano de preparação para o vestibular.

A Figura 3 traz a comparação entre aprovados e reprovados nas duas condições do vestibular (alta exigência e média exigência), no que diz respeito à frequiência de elaboração de resumos com as próprias palavras durante as sessões de estudo no ano de preparação para o vestibular. Os reprovados em alta exigência utilizam-se da estratégia de produzir resumos compreensivos das disciplinas do vestibular com maior freqüência que os aprovados. Cinqüenta por cento dos reprovados declarou fazê-lo na maior parte de suas sessões de estudo e somente a proporção de 0,40 dos aprovados dizem fazer resumos com alta frequiência.

口Aprovados Alta 口Reprovados Alta

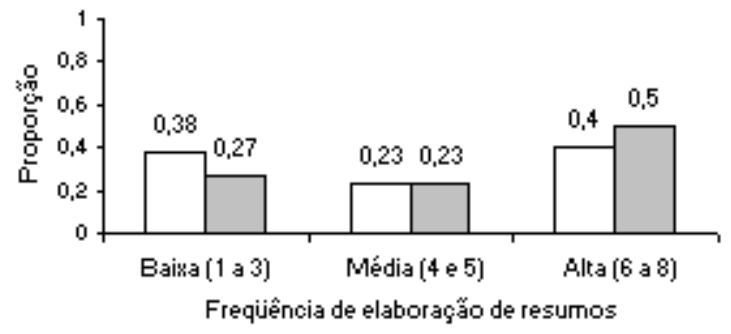

Além disso, mais aprovados declaram elaborar resumos em poucas sessões de estudo: 0,38 , contra 0,27 dos reprovados. Na condição de média exigência, proporcionalmente mais aprovados $(0,35)$ estudam na maior parte das sessões de estudo para o vestibular em comparação com os reprovados: nenhum reprovado afirmou fazer resumos com essa intensidade. As proporções de reprovados que declaram elaborar resumos com freqüências baixas e médias são superiores: 0,61 e 0,38 respectivamente, enquanto as dos aprovados são 0,48 e 0,17 .

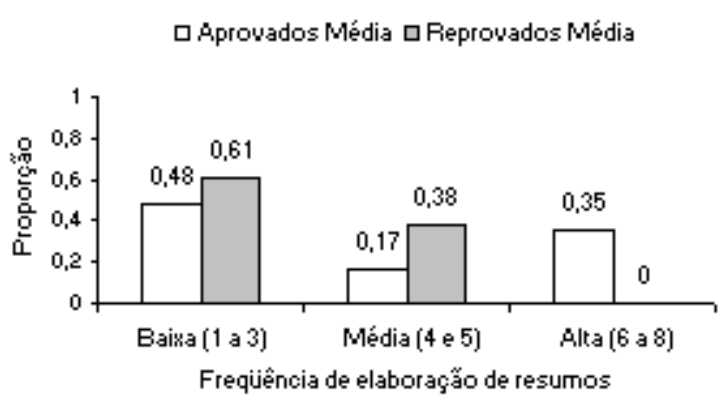

Figura 3: Distribuição das proporções de sujeitos que prestaram provas para o vestibular nas condições de exigência alta e média no que diz respeito à frequiência de elaboração de resumos durante o ano de preparação para o vestibular

Na Figura 4 estão representadas as freqüências de emprego de processos de esquematização em sessões de estudo por parte dos participantes que prestaram vestibular nas duas condições de exigência. Nos participantes de alta exigência, embora existam algumas diferenças, como por exemplo uma maior proporção de participantes reprovados que empregam essa estratégia com alta freqüência e maior percentual de aprovados que criam esquemas com média freqüência, essas diferenças são pouco expressivas quanto às suas magnitudes. É possível constatar que os dois grupos apresentam semelhanças no que diz respeito à utilização de processos de esquematização. Observando os dados dos estudantes de média exigência, é possível afirmar que os aprovados utilizam-se desse tipo de procedimento com maior freqüência, mesmo ao constatar que uma proporção ligeiramente maior de reprovados esquematiza com alta frequiência $(0,38$ dos reprovados e 0,35 dos aprovados situam-se nessa faixa). Isso é contrabalançado por uma proporção menor de aprovados $(0,30)$ na faixa de baixa freqüência de utilização da esquematização e uma proporção consideravelmente maior na faixa de média frequiência. Portanto, os aprovados são razoavelmente bem distribuídos nas três faixas de frequiência enquanto nos reprovados predominam participantes que esquematizam com baixa freqüência. 
口Aprovados Alta qReprovados Alta

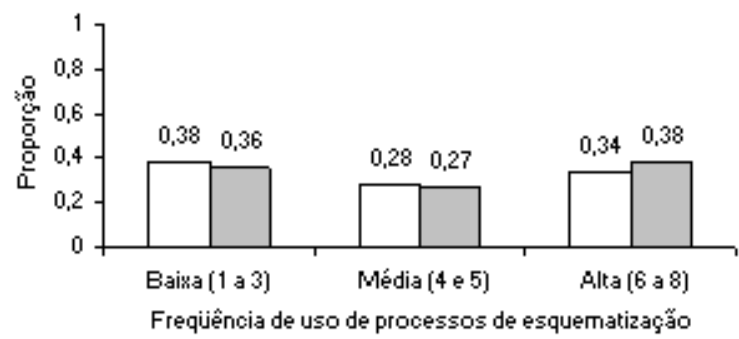

口. Aprovados Média qReprovados Média

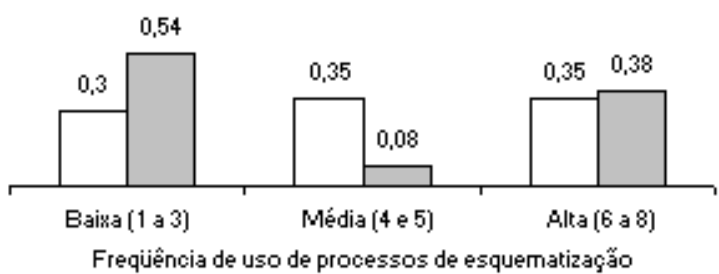

Figura 4: Distribuição das proporções de sujeitos que prestaram provas para o vestibular nas condições de exigência alta e média no que diz respeito à freqüência de uso de processos de esquematização durante o ano de preparação para o vestibular.

Como é ilustrado na Figura 5, há uma proporção consideravelmente maior $(0,72)$ de participantes aprovados em alta exigência que resolvem exercícios de vestibulares de anos anteriores da universidade para a qual prestaram exame, em comparação com os reprovados $(0,50)$. Há também diferença evidente no que diz respeito ao percentual de participantes que resolvem exercícios de vestibulares passados em uma proporção mediana das sessões de estudo: cerca de 0,27 dos reprovados em alta exigência situam-se sob essa

口Aprovados Alta 口Reprovados Alta

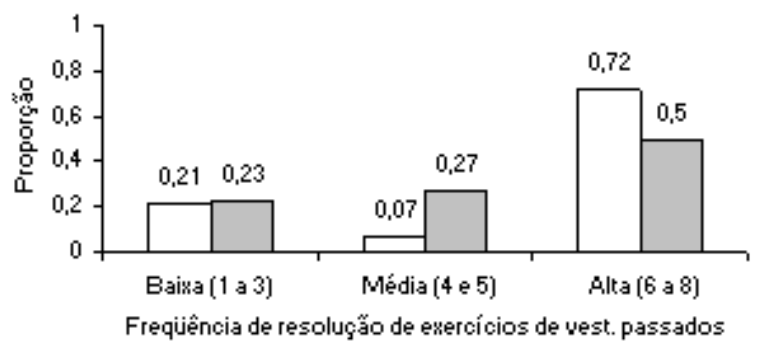

categoria, enquanto 0,07 dos aprovados encontram-se na mesma situação. Já as proporções dos participantes aprovados e reprovados na condição de média exigência que resolvem exercícios de vestibulares passados são próximas nos três tipos de freqüência. Há ligeira superioridade dos aprovados nas faixas de baixa e média freqüência, enquanto uma proporção maior de reprovados afirma resolver exercícios desse tipo em grande parte das sessões de estudo: 0,54, comparados a 0,44 dos aprovados.

口Aprovados Média uReprovados Média

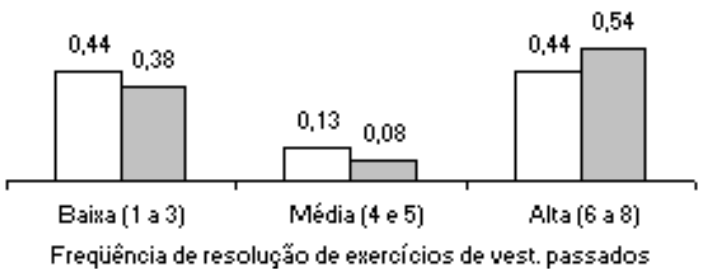

Figura 5: Distribuição das proporções de sujeitos que prestaram provas para o vestibular nas condições de exigência alta e média no que diz respeito à frequiência de resolução de exercícios de vestibulares passados para a universidade durante o ano de preparação para o vestibular.

Assim como ocorre com os exercícios passados do vestibular para que os participantes prestaram exame, é possível observar a existência de diferenças grandes entre aprovados e reprovados em alta exigência quanto à frequiência de resolução de exercícios de outros vestibulares (ver Figura 6). Há uma diferença de 0,19 favorável aos aprovados no que diz respeito à proporção de participantes que estuda resolvendo esses tipos de exercícios na maior parte das sessões de estudo. Já entre os participantes que resolvem exercícios em proporções baixas e medianas da quantidade de sessões de estudo, os reprovados apresentam maio- res proporções. Entre os participantes na condição de média exigência, de modo geral, os aprovados empregam esse procedimento com maior frequiência que os reprovados. Uma maior proporção de aprovados declara resolver exercícios com alta frequiência em relação aos reprovados: 0,69 , contra 0,54 . Além disso, as proporções de participantes que dizem resolver exercícios com freqüência média são próximas e baixas (inferiores a 0,1$)$. Na faixa de baixa freqüência, há maior proporção de reprovados $(0,38)$ que de aprova$\operatorname{dos}(0,22)$. 
口Aprovados A.tra uReprovados Alta

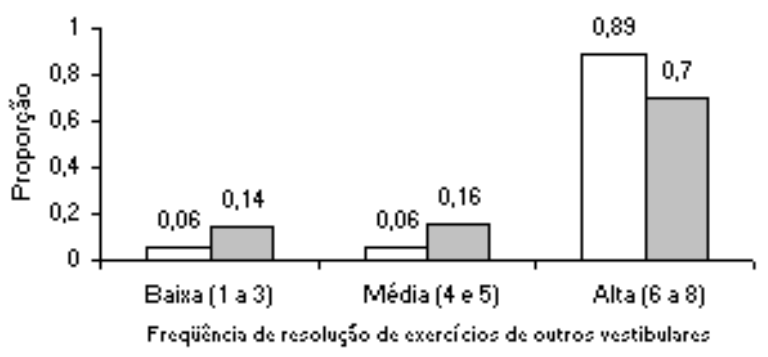

口Aprovados Média uReprovados Média

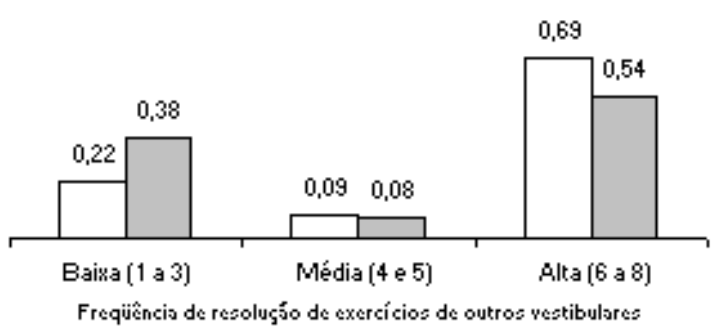

Figura 6: Distribuição das proporções de sujeitos que prestaram provas para o vestibular nas condições de exigência alta e média no que diz respeito à freqüência de resolução de exercícios de vestibulares de outras universidades durante o ano de preparação para o vestibular.

\section{DISCUSSÃO}

Tanto entre participantes que prestaram vestibular na condição de alta exigência quanto entre os que prestaram para média exigência, a tendência é de que sejam usadas estratégias de destaque com alta freqüência durante a preparação para o vestibular. A Figura 1 indica que os participantes reprovados empregam essa estratégia mais que os aprovados e a diferença entre eles é maior dentre os participantes que prestaram vestibular para média exigência.

No que diz respeito a memorizar informações, o outro procedimento integrante do primeiro bloco, composto por atividades de repetição e menor sofisticação, foram observados padrões menos discrepantes de freqüência de uso dessa estratégia entre aprovados e reprovados. Mesmo assim, como é mostrado na Figura 2, os reprovados em ambas as condições de exigência relataram terem utilizado esse procedimento com freqüência ligeiramente maior.

Isso mostra que os reprovados empregam procedimentos caracterizados pela repetição e realce simples de informações com mais freqüência que os aprovados, durante a preparação para a prova. Em decorrência desses resultados, é possível concluir que esses procedimentos não contribuem muito para o sucesso na prova. Se esse fosse o caso seria esperado observar grande proporção de aprovados utilizando procedimentos desse bloco.

No que diz respeito à elaboração de resumos como procedimento para estudar para o vestibular, são observadas diferenças menores nas frequiências de utilização dessa atividade por aprovados e reprovados na condição de alta exigência (ver Figura 3). Ainda assim, é observada uma freqüência de utilização de resumos um pouco maior por parte dos reprovados nessa condição. Por outro lado, entre os participantes que enfrentaram a condição de exigência mediana, é claramente maior a proporção de aprovados que elaboram resumos com alta freqüência: metade dos participantes fez isso, enquanto nenhum dos reprovados em média exigência fez resumos com essa intensidade.
Ao verificar os padrões de distribuição de frequiências de uso de estratégias de esquematização apresentados por aprovados e reprovados nas duas condições de exigência (Figura 4) é perceptível que entre os participantes de alta exigência a distribuição entre os três graus de freqüências é razoavelmente eqüitativa tanto em aprovados quanto em reprovados. Já dentre os participantes que prestaram vestibular para a condição de média exigência é observado que os participantes aprovados também apresentam distribuição equiitativa, enquanto que mais da metade dos reprovados esquematizou conteúdos com baixa freqüência durante o ano.

As frequiências de utilização dos procedimentos do bloco intermediário, que compreende atividades de maior complexidade que as do primeiro bloco são diferenciadas em relação aos procedimentos marcados pela repetição. É observado que os aprovados e reprovados na condição de alta exigência apresentam distribuições semelhantes em relação aos dois procedimentos. Já entre os aprovados e reprovados em média exigência as distribuições são mais irregulares, possivelmente devido à menor quantidade de participantes. Os resultados indicam que os aprovados nessa condição fazem resumos mais freqüentemente e esquematizam com menos regularidade que os reprovados.

Ao fazer referência à freqüência de utilização dos procedimentos do bloco de resolução de exercícios (Figuras 5 e 6), é verificado que os aprovados em alta exigência adotam essa atividade com mais frequiência que os reprovados. Já na condição de média exigência os reprovados fazem exercícios de vestibulares anteriores da instituição na qual desejam ingressar com freqüência ligeiramente superior que os aprovados, mas a situação inverte-se consideravelmente em relação aos outros exercícios resolvidos. Comparando-se os dados referentes às duas condições, é observado que apresentam padrão semelhante de distribuição, embora dentre os participantes de alta exigência ocorra maior concentração na área de alta freqüência tanto dentre aprovados quanto reprovados, e, conseqüentemente, menores proporções nas freqüências baixa e média.

Considerando os resultados referentes aos participantes que prestaram vestibular para a condição de 
alta exigência, é possível observar, por meio dos resultados obtidos com os três blocos de procedimentos, três padrões nas distribuições. Enquanto os reprovados utilizam com maior freqüência os procedimentos memorizar e destacar informações (primeiro bloco), é menos precisa a percepção de quem utiliza os procedimentos do segundo bloco (resumir e esquematizar) com maior frequiência: os dois grupos apresentam maior similaridade em suas distribuições. Já no que diz respeito aos procedimentos do terceiro bloco, voltado para a resolução de exercícios, é evidente que mais aprovados os empregam com alta freqüência que reprovados.

Levando em conta que o estudo provavelmente desempenha papel importante para determinar o sucesso ou fracasso numa prova acadêmica, as diferenças referentes a procedimentos utilizados por aprovados e reprovados numa prova de exigência de desempenho como o vestibular podem explicar parcialmente sua performance nessa situação. E pertinente apontar que numa investigação anterior (Wachelke \& Botomé, 2004) não foram encontradas diferenças de grande magnitude no modo como os participantes que prestaram provas para uma mesma condição de exigência administram seu estudo no tempo, o que favorece o entendimento de que as particularidades encontradas no gerenciamento dos procedimentos de estudo possuem algum peso no resultado dessas provas.

Analisando os resultados obtidos, a tendência é considerar que os procedimentos voltados para a resolução de exercícios são os mais indicados para contribuir para a aprovação, pelo menos em provas de vestibular ou outras semelhantes a elas. Isso se deve ao resultado de que uma proporção maior de aprovados que de reprovados declarou utilizar essas práticas com alta freqüência, o que não foi encontrado claramente no contexto dos outros procedimentos estudados.

Surge então a questão: por que resolver exercícios é a maneira mais adequada de preparação para o vestibular, o contexto de exigência que foi investigado? Resolver exercícios, além de exigir do estudante uma participação mais ativa, é um procedimento que estimula a desenvolver exatamente a classe de respostas que são exigidas numa prova de vestibular: empregar o conhecimento para resolver problemas. É importante ressaltar que, para ser bem sucedido na resolução de exercícios, um indivíduo freqüentemente precisa ler textos e identificar aspectos importantes do material de estudo para encontrar soluções para os problemas com que se depara, mas é o uso disto ao resolver problemas que efetivamente pode preparar para o tipo de prova que os estudantes deverão enfrentar.

Segundo Botomé (1979), comportamentos caracterizados pela elaboração de assuntos, como no presente caso resolver questões de vestibular aplicando conceitos e assuntos de apostilas e livros-textos, são preferíveis em relação a comportamentos de repetição como sublinhar palavras e frases ou copiar trechos textuais. Estes últimos podem até mesmo ser considerados irrelevantes para o processo educacional, uma vez que nada acrescentam para que seja alcançado o comportamento terminal: resolver com sucesso um problema apresentado em uma prova de desempenho, a forma específica de exigência de desempenho investigada no presente estudo.

Essa constatação, bem como os resultados obtidos, possuem implicações significativas para instituições educacionais que aplicam provas ou preparam seus estudantes para testes ou concursos. É de responsabilidade dessas instituições estimular o treino de comportamentos adequados para a realização de verificações acadêmicas de desempenho. No entanto, muitas vezes não é dada ênfase à necessidade de um repertório ativo para os estudantes, o que acarreta no emprego de respostas passivas por partes deles.

$\mathrm{O}$ ensino direcionado a estudantes que passam ou passarão por situações de exigência de desempenho consiste geralmente numa solução que não possui ligação com a necessidade que motiva essa aprendizagem. Isso contraria o que afirma Mager (1973) em seu livro sobre análise de objetivos de aprendizagem: "para que o ensino seja frutífero, tem que haver uma conexão entre o problema e sua solução, entre a necessidade e a natureza da instrução" (p. 13). Uma vez que os processos de aprendizagem têm por objetivo propiciar a passagem de uma situação artificial facilitadora para uma situação em que um comportamento terminal possa ocorrer em condições naturais (Botomé, 1977), é necessário, por meio do ensino, estimular comportamentos cada vez mais próximos dos que idealmente ocorrem em situações de prova. Não basta incentivar estudo ou procedimentos de aprendizagem sobre os assuntos das provas; é preciso também que os estudantes aprendam como proceder durante a realização de testes, provas ou exigências.

A princípio se poderia pensar que os estudantes são bem preparados para realizar provas com exigência de desempenho como o vestibular, uma vez que várias escolas trazem em seu material didático exercícios de vestibulares passados, ou exercícios semelhantes ao que é solicitado em vestibulares. No entanto, a presença desses exercícios no material e sua correção por professores não garante que os estudantes dêem a preferência que seria indicada à resolução de exercícios, em comparação com outros procedimentos de estudo empregados no estudo individual fora de sala de aula.

Os estudantes certamente resolvem muitos exercícios no decorrer de suas vidas acadêmicas, até mesmo porque provas e testes são uma realidade constante em escolas. Entretanto, situações de exigência de desempenho de caráter mais amplo, como provas de concursos ou o próprio vestibular, possivelmente não são como provas comuns em que os assuntos avaliados 
são trabalhados nas semanas anteriores à situação de testagem. Nesses casos, existe a possibilidade de que os estudantes optem por dar preferência a procedimentos de destaque de informação, a despeito de terem à disposição uma grande quantidade de exercícios para serem resolvidos. É nesse sentido que caberia às instituições educacionais ensinar a relevância e os modos de resolver exercícios também para provas mais complexas. De toda maneira, cabe ressaltar o caráter de suposição dessas últimas afirmações.

Os resultados referentes aos participantes que se prepararam para a prova de exigência mediana podem ser interpretados somente com muita cautela. As amostras dessa condição de exigência, menores e desiguais em termos de tamanho, favorecem uma eventual distorção dos dados em relação à população que representam, bem como dificultam uma comparação entre os grupos. Discutir mais prolongadamente os resultados obtidos com esses grupos é uma tarefa arriscada que provavelmente levaria a conclusões com pouca base ou fundamentação. Portanto, para que sejam alcançados resultados mais confiáveis, é recomendável realizar uma investigação semelhante com mais participantes.

Ainda que, com essas ressalvas, os resultados encontrados com participantes que prestaram provas de exigência mediana apresentam-se distintos dos encontrados com participantes que prestaram provas para a condição mais difícil. Emergem algumas hipóteses dos resultados obtidos, as quais poderiam orientar estudos futuros. No contexto do vestibular, quando o desempenho exigido para aprovação não é tão rigoroso quanto o que é observado em vestibulares altamente concorridos (caso do vestibular de medicina), os alunos que não resolvem exercícios com muita freqüência, dando preferência a procedimentos mais passivos e menos trabalhosos em termos de esforço, podem obter sucesso. A preparação da maioria dos candidatos nesses vestibulares de concorrência menor seria, em decorrência disso, menos sistemática.

Já no contexto de vestibulares altamente disputados isso não acontece: a exigência de alto rendimento é conhecida pelos estudantes, que se vêem forçados a estudar de maneira mais organizada. Assim, a prova seleciona apenas os alunos mais capacitados a resolver problemas, habilidade desenvolvida principalmente por meio do treino de exercícios.

De todo modo, é importante explicitar algumas implicações das escolhas metodológicas da investigação, para contextualizar a interpretação dos dados. As conclusões referentes a proporções de participantes que declararam usar os procedimentos observados baseiam-se numa inspeção visual dos dados, e por esse motivo são restritas à amostra da pesquisa. Devido à não-utilização de testes estatísticos, não cabe generalizar os resultados a uma população mais am- pla. O presente estudo, voltado para a descrição preliminar do fenômeno, possui caráter exploratório.

Os resultados encontrados fornecem algumas opções de rumos a serem seguidos em investigações subsequientes com a finalidade de aprofundar o conhecimento sobre o comportamento de estudar frente a exigências de desempenho. Além da mencionada necessidade de replicar o estudo com amostras de participantes em condição de média exigência, um curso de ação a ser seguido consiste em ampliar o conjunto de procedimentos a ser examinado na preparação para o vestibular.

Uma alternativa a ser explorada são os comportamentos privados de cada participante que ocorrem durante o ato de estudar, na forma de estratégias para lidar com a informação em graus diferenciados de profundidade (Entwistle, 1988). Os comportamentos de estudar que ocorrem em ambiente privado equivalem-se basicamente aos processos de pensar sobre os próprios pensamentos (Dembo, 1988). Essas estratégias variam desde tentar integrar informações novas a conhecimento e experiências já existentes, até simplesmente memorizar informações sem se preocupar com seu sentido ou relações com outras informações. Mesmo que dois estudantes façam uso de um mesmo procedimento para preparar-se para uma prova como, por exemplo, a elaboração de resumos sobre os assuntos estudados, é possível que as estratégias para lidar com as informações com que se deparam durante o estudo sejam diferentes. Por sua vez, estratégias distintas possuem papéis diferenciados no que se refere à predição de desempenho em exames acadêmicos (Elliot, McGregor \& Gable, 1999).

Finalmente, outra possibilidade de seguimento aos estudos nessa linha envolve a adoção de uma linha de investigação que permita manipular variáveis, isto é, a realização de pesquisas experimentais. $O$ presente estudo é uma pesquisa comparativa, cuja vantagem reside no alto grau de envolvimento dos participantes para com a condição de exigência de desempenho estudada: o vestibular. O exame possui forte significado na vida da maior parte dos participantes e favorece a observação do fenômeno de interesse da pesquisa. No entanto, possui limitações de controle de variáveis que interferem no fenômeno, característica comum em estudos de campo, enquanto opções metodológicas: se por um lado são realistas, por outro não permitem grau suficientemente preciso de controle de variáveis por parte dos pesquisadores (Tajfel, 1978).

Dois aspectos do estudo sugerem aprimoramentos em replicações futuras ou execução de investigações voltadas para os comportamentos de estudar. Em primeiro lugar, ainda que seja argumentado que o vestibular, por ser importante para os participantes, favoreça a observação dos comportamentos de interesse, é evidente que existe margem para imprecisões significativas na rememoração dos participantes sobre o que fizeram no ano anterior. Não se pode afirmar com 
segurança de que suas declarações de utilização de procedimentos sejam fidedignas, ou mesmo que os participantes sejam qualificados para avaliar as freqüências de emprego dessas estratégias. Nisso consiste uma limitação da pesquisa, apontando para a necessidade de refinamento da medida utilizada e do modo de proceder para coletar dados.

O segundo aspecto está vinculado à impossibilidade de estabelecer relações causais a partir dos dados, que foram gerados por um delineamento nãoexperimental de caráter correlacional. Apesar de que seja possível pressupor uma certa causalidade para explicar o fenômeno, inferências desse tipo são empregadas essencialmente como recursos para tornar coerentes alguns resultados, não se sustentando especificamente no método empregado. Um delineamento experimental seria necessário para fazer inferências desse tipo com maior propriedade. Para testar as descobertas referentes ao fenômeno investigado, é pertinente construir experimentos sob condições mais controladas que reproduzam o estudo para provas acadêmicas, possibilitando aos pesquisadores caracterizar com maior precisão as relações entre as variáveis de interesse.

Finalmente, é pertinente esclarecer que, ao apontar que certos procedimentos de estudo estão associados a um maior desempenho em exames acadêmicos, não se quer significar que essas estratégias representem necessariamente bons caminhos para uma formação intelectual sólida. Seria esse o caso se fosse possível argumentar que provas como o vestibular são medidas válidas e confiáveis de uma grande variedade de conhecimentos escolares importantes. Trata-se de uma questão complexa e que gera intensos debates na sociedade acerca da adequação desse tipo de recurso para admissão em instituições de ensino superior. Contudo, em momento algum da pesquisa foi visado enfocar a situação de exigência de desempenho sob essa perspectiva; os objetivos dela estiveram restritos a um estudo de correlatos, em termos de procedimentos de estudo, do resultado numa prova de desempenho. O exame vestibular foi determinado meramente como contexto de ocorrência do fenômeno, por algumas razões mencionadas.

\section{REFERÊNCIAS}

Boruchovitch, E. (1999). Estratégias de aprendizagem e desempenho escolar: considerações para a prática educacional. Psicologia: Reflexão e Crítica, 12(2), 361-376.
Botomé, S. P. (1977). Descripción de una muestra de un programa de enseñanza sobre como desarrollar programas de enseñanza (modificación de comportamiento) destinado a estudiantes de los dos ultimos años de psicología de la Universidad Pontifícia Católica de San Pablo (SP) - Brasil. Trabalho apresentado em Oficina sobre Instrução Individualizada no Instituto Universitário Pedagógico, Caracas.

Botomé, S. P. (1979). Questões de estudo: uma condição para instalar discriminação de aspectos importantes de um texto. Psicologia, 5(2), 1-27.

Dembo, M. H. (1988). Applying educational psychology in the classroom ( $3^{\mathrm{a}}$ ed.). New York: Longman.

Elliot, A. J., McGregor, H. A. \& Gable, S. (1999). Achievement goals, study strategies and exam performance: a mediational analysis. Journal of Educational Psychology, 91(3), 549-563.

Entwistle, N. (1988). Motivational factors in students' approaches to learning. Em Schmeck, R. (Ed.) Learning strategies and learning styles: perspectives on individual differences (p. 2151). New York: Plenum Press.

Jabur, M. A. (1976). Efeito do local de estudo no comportamento de estudar. Modificação de Comportamento: Pesquisa e Aplicação, 1(1), 19-31.

Mager, R. F. (1973). Análisis de metas. México: Trillas.

Mazzoni, G. \& Cornoldi, C. (1993). Strategies in study time allocation: why is study time sometimes not effective? Journal of Experimental Psychology: General, 122(1), 47-60.

Son, L. K. \& Metcalfe, J. (2000). Metacognitive and control strategies in study-time allocation. Journal of Experimental Psychology: Learning, Memory, and Cognition, 26(1), 204221.

Metcalfe, J. (2002). Is study time allocated selectively to a region of proximal learning? Journal of Experimental Psychology: General, 131(3), 349-363.

Nelson, T. O. \& Leonesio, R. J. (1988). Allocation of self-paced study time and the "labor-in-vain effect". Journal of Experimental Psychology: Learning, Memory, and Cognition, 14(4), 676-686.

Nelson, T. O. (1993). Judgements of learning and allocation of study time. Journal of Experimental Psychology: General, $122(2), 269-273$

Skinner, B. F. (1953). Science and human behavior. New York: MacMillan.

Skinner, B. F. (1967). Ciência e comportamento humano. Brasília: Coordenada.

Tajfel, H. (1978). Social psychology as a social science. Em H. Tajfel \& C. Fraser Introducing social psychology (pp. 21-53). Middlesex: Penguin.

Wachelke, J. F. R. \& Botomé, S. P. (2004). Comportamento de vestibulandos em relação a organização, gerenciamento e alocação do estudo em períodos de tempo. Interação em Psicologia, 8(2), 271-286.

\section{Sobre os autores:}

João Fernando Rech Wachelke: Bacharel em Psicologia. Endereço para correspondência: Departamento de Psicologia da Universidade Federal de Santa Catarina. - R. Octavio Lebarbenchon, 69, Santa Mônica, Florianópolis - SC. 88037-290. Telefone: (48) $233-3785$. Endereço eletrônico: wachelke@yahoo.com.

Sílvio Paulo Botomé: Doutor em Psicologia. Endereço eletrônico: botome@cfh.ufsc.br. 
